\title{
P-17 LIBYA - A NEW DEPTH-TO-BASEMENT INTERPRETATION FROM POTENTIAL FIELDS DATA CONSTRAINED BY WELL DATA
}

S.Z. JASSIM, S.J. CAMPBELL and I.W. SOMERTON

Getech Ltd, Leeds University, School of Earth Sciences, Leeds LS2 9JT, UK

\begin{abstract}
:
Oil exploration companies have collected gravity and magnetic data in Libya for over 50 years. In fact, potential field methods were among the original geophysical techniques used to map and delineate oilbearing structures in Libya prior to the introduction of the seismic reflection method. They still remain cost effective methods, but now tend to be used in support of the seismic method. Changes in gravity occur where there are lateral changes in rock density e.g. across faults or over anticlines. The magnetic method maps small changes in the geomagnetic field caused by lateral changes in magnetic susceptibility. Since sedimentary rocks are generally less dense than basement rocks, then a significant component of gravity anomalies comes from the sedimentary interface with the basement. If intra-sedimentary volcanics are present within a basin, then they will produce strong magnetic anomalies that can mask the signal coming from the deeper basement interface. Hence both types of data complement each other when trying to understand the intra sedimentary structures and morphology of the underlying basement.
\end{abstract}

The horizontal and/or vertical gradients of potential field data help to map the positions of faults and anticlines at shallow depths within the basin, as well as deeper basement structures. The reduction-to-pole transform makes the magnetic anomalies simpler in shape and easier to interpret. Derivatives also yield important information on the sources of the signals, their continuity, depth and character. As with all interpretations of potential field data there is an inherent ambiguity that can be minimized by utilizing the full spectral content of anomalies and linking the inferences drawn from the data with hard geological control.

Data and geophysical interpretation: The figures below show the available potential fields data over Libya. Many recent proprietary surveys have not been included. Data from the neighbouring countries (not shown) were also available to the study and these provided controls on the continuity and importance of structures close to the Libya borders. Regional exploration well data were available to the study to help constrain the potential field interpretation.

Automated depth estimations from the magnetic data were generated using $2 \mathrm{D}$ and $3 \mathrm{D}$ Euler deconvolution techniques. These solutions give estimates of the location and depth of the sources of the magnetic signals, (either inter-sedimentary volcanics or basement), and also information on the strike, dip and susceptibility contrast of the structures causing the anomaly.

The isostatic residual gravity field was calculated by removing the regional isostatic field, determined from the topographic/bathymetric model, from the Bouguer anomaly,. This minimizes the effect of any long-wavelength gravity anomalies (greater than $\sim 200 \mathrm{~km}$ ) generated from variations in the Moho' depth. This residual field was used to constrain several 2-D models across the major basins. Lithology densities were derived from well log measurements and documented measurements on core samples.

A 3D inversion of the gravity data to delineate the high-density basement surface was attempted. In areas where both gravity and magnetic data were available, the basement depths estimated from both methods

EAGE Conference on Geology and Petroleum Geology - St. Julians, Malta, 1 - 4 October 2000 
were compared. Inconsistencies were addressed by investigating a number a possible causes; lateral variations in density of the sediments, Moho variations, basement type, magnetic remanence etc, until an acceptable depth, consistent with all the known evidence, was reached.

Geological interpretation: This study initially undertook a thorough overview of the available well 'tops' data to produce a preliminary set of horizon maps for each of the main basins. Away from the hundred or so basement control points (well data) the potential fields methods were used to provide the appropriate interpolation and extrapolation of the derived horizons.

Emphasis has been put on the unconformity surfaces and the sequences between them to decipher the complex geology and tectonic history of the country. The Sirte Unconformity below the Upper Cretaceous sequence is largely restricted to the northern part of Libya and represents a widely variable erosional subcrop ranging from Precambrian to Lower Cretaceous. South of the Sirte and Ghadamis basins, the Lower Cretaceous Nubian unconformity, a prominent feature of the Egyptian stratigraphic column, is the most prominent Cretaceous unconformity with similarly varied subcrop from Precambrian to Jurassic.

The "Hercynian" unconformity, where preserved in Libya is located largely at the base of the Triassic rather than the Upper Permian, (as is the case in Northern Arabia), and apart from in a few wells, the Upper Permian is largely absent in Libya. The "Caledonian" event is characterised by two unconformities below and above a syn-tectonic sequence. This "Syn-Caledonian" sequence is of Devonian age and, where absent, the Carboniferous sits directly on Silurian or older rocks and is referred to as the U Devonian unconformity. The L Devonian unconformity lies between the Upper Silurian and Devonian. Occasionally, on outcrops, Devonian rocks were found to rest on the Precambrian basement directly.

The study of the thickness variations, the subcrops of unconformities and the tectonic elements derived both from geophysical and geological interpretations resulted in a better understanding of the tectonic development of Libya. A new tectonic map, stressing the tectonic zonation, is especially important tool in understanding the hydrocarbon maturity.

This study illustrates what can be achieved in terms of regional basin analysis using available potential field data, and it is hoped this study can be extended into the broader Mediterranean region once GETECH's Mediterranean Magnetic Study is complete.

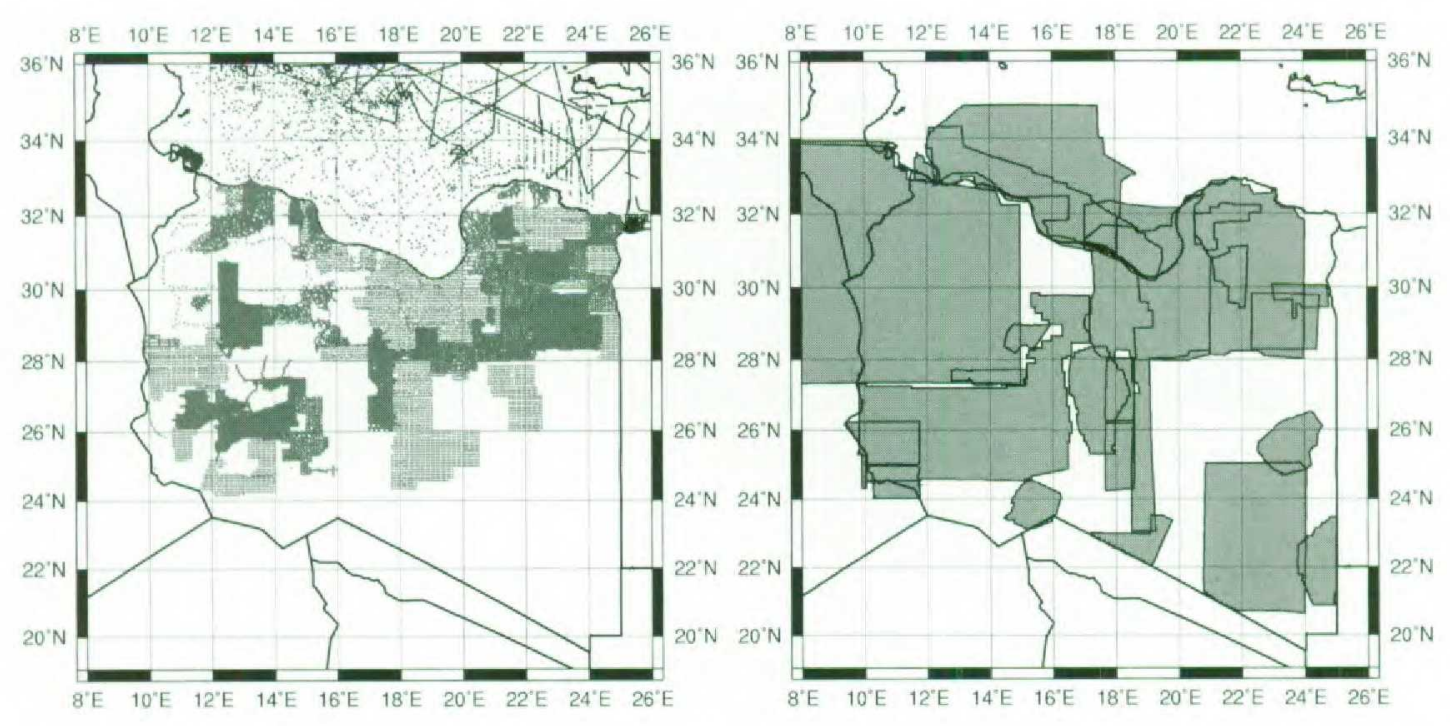

Gravity Coverage of Libya

Magnetic Coverage of Libya 